\title{
Comparative Study between The Refractive Outcome Following Phacoemulsification and Small Incision Cataract Surgery
}

Abdel Mongy El Sayed Ali ${ }^{1}$, Abdulla Mohammed Al Amin Abdulla ${ }^{1}$, Ahmed Ibrahim Howaidy ${ }^{2}$, and Reham Mahmoud Ahmed Mohammed ${ }^{2 *}$

Department of Ophthalmology, Faculty of Medicine, ${ }^{1}$ Al-Azhar University and ${ }^{2}$ Aswan University

*Corresponding author: Reham Mahmoud Ahmed Mohammed, Mobile: $( \pm 20) 01060649543$, E-Mail: dr.riri90@gmail.com

\begin{abstract}
Background: phacoemulsification is the preferred technique for cataract surgery for most surgeons. An alternative surgical technique MSICS has been gaining popularity, because of this technique has been shown to yield comparable surgical outcomes as phacoemulsification.

Objective: In our study we compared the two techniques as regard their effect on visual acuity, surgically induced astigmatism (SIA).

Patients and Methods: forty patients were included in this study. Patients were divided into two groups: Group A (20 patients) underwent phacoemulsification and Group B (20 patients) underwent MSICS.

Results: both groups were studied preoperatively and postoperatively regarding uncorrected visual acuity (UCVA), best corrected visual acuity (BCVA) andsurgically induced astigmatism (SIA). We found that both techniques give excellent postoperative visual results and that the SIA was $0.43 \pm 0.25$ in phacoemulsification group and $0.61 \pm 0.55$ in MSICS group at 3 month postoperative with no statistical difference between both groups ( $\mathrm{p}=0.348)$.

Conclusion: according to our study, it is recommended for all surgeons to master MSICS technique for its excellent results which are comparable to phacoemulsification. For the beginners it could be considered like a step to phacoemulsification due to many common steps between the two techniques, also for expert surgeons it could be useful and can replace phacoemulsification efficiently in very hard nuclei and could be done if conversion is decided during phacoemulsification surgery.
\end{abstract}

Keywords: Phacoemulsification, SIA, MSICS

\section{INTRODUCTION}

Senile cataract is an age related, vision impairing disease characterized by gradual, progressive thickening of the lens. It is one of the world's leading causes of avoidable blindness (1). All techniques of cataract extraction are being modified to achieve best uncorrected visual acuity and early rehabilitation ${ }^{(2)}$.

The evolution of cataract surgical techniques over the past several decades has been associated with a progressive decrease in the size of the cataract incision. Wound size has progressively decreased from $12.0 \mathrm{~mm}$ in intracapsular cataract surgery about to $10.5 \mathrm{~mm}$ in early extracapsular surgery and about $5 \mathrm{~mm}$ with the advent of phacoemulsification. The widespread use of foldable intraocular lens (IOL) has allowed the cataract wound to decrease to $3.0 \mathrm{~mm}$ or smaller ${ }^{(3)}$.

MSICS has the advantages of relatively small suturless incisions regarding early wound stability, less postoperative inflammation, and no suture-related complications such as those in conventional ECCE. It also has the advantage of being manual with no ultrasound-related complications such as those in phacoemusification ${ }^{(4)}$.

In phacoemulsification, the duration of surgery, phacoemulsification power used, and even the incidence of intraocular complications vary with the nucleus density. In MSICS, the time spent on nucleus delivery does not vary from patient to patient. Hence, the manual small incision techniques are gaining popularity, as they are quick, relatively inexpensive techniques for largescale cataract management in the developing world ${ }^{(5)}$.
Driven by the need for more cost effective options, an increasing trend in developing countries is the use of manual suturless small incision cataract surgery (SICS), which some have claimed is comparable to phacoemulsification in terms of obtaining excellent visual outcomes, faster, less costly and has fewer complications $^{(6)}$.

\section{AIM OF THE WORK}

It is to compare between the postoperative visual outcomes of cataract extraction performed by conventional ultrasonic phacoemulsification and suturless small incision cataract surgery in senile cataract as regard surgical induced astigmatism (SIA).

\section{PATIENTS AND METHODS}

Study Design:

The study was conducted as a prospective, randomized study, where 40 eyes of 40 patients were assigned randomly from the outpatient clinic among patients complaining of gradual painless drop of vision and diagnosed as senile cataract.

The subjects of the study were divided into two groups: Group A: 20 eyes who underwent cataract extraction using conventional phacoemulsification. Group B: 20 eyes who underwent cataract extraction using the Small Incision Cataract Surgery (SICS).

\section{Written informed consent:}

An approval of the study was obtained from AlAzhar University Academic and Ethical Committee. 


\section{Every patient signed an informed written consent for acceptance of the operation. \\ Methods: \\ 1- Preoperative Examination:-}

Following detailed medical and ophthalmic history, all cases were subjected to refraction which was not applicable in all cases due to the very dense cataract, assessment of uncorrected visual acuity (UCVA) and best corrected visual acuity (BCVA) with Landolt c chart, external ocular examination and slit lamp examination of eye lids conjunctiva, cornea, anterior segment, assessment of type and, density of cataract which has been graded at the slit lamp.

The IOP was measured using a goldmann applanation tonometer and the posterior segment examination was done usinga \pm 90 diopters lens for slit lamp fundus biomicroscopy considering $\mathrm{B}$ scan ultrasonography whenever cataract density prevents good visual fundus assessment.

\section{Preoperative assessment:}

All the cases are subjected to the following:

a) keratometry:

Javal schiotz keratometer was used to measure k reading.

b) Biometry:

A-scan (SONOMED PAC SCAN PLUS 300) was used to measure the axial length then IOL power was calculated by using the suitable formula according the axial length.

\section{2- Operative Procedures:}

A. Preoperative preparation: Pupillary dilatation was done by topical application of Tropicamide $1 \%$ eye drops every 15 minutes starting one hour before the operation.

B. Anesthesia: The operative procedures were performed under local anesthesia using a mixture of Lidocaine Hcl 2\% (Xylocaine 2\%) and Bupivican $\mathrm{Hcl}$ 0.75\% (Marcaine), $5 \mathrm{ml}$ for peribulbar injection in the inferotemporal quadrant of the orbit and when needed additional 1 to $2 \mathrm{ml}$ was injected direct nasally.

\section{Surgical procedures:}

I) Phacoemulsification:

1) Sterilization and draping.

2) Application of a wire speculum.
3) A disposable ophthalmic $3.2 \mathrm{~mm}$ keratome was used to construct corneal tunnel in the upper temporal quadrant of about $2 \mathrm{~mm}$ length and $3.2 \mathrm{~mm}$ width, then an adequate amount of OVD was injected to fill the anterior chamber and flatten the anterior capsule of the lens for proper subsequent capsulorrhexis procedure.

4) A Continuous Curvilinear Capsulorrhexis (CCC) was performed with a self-fashioned cystotome using a bent 27 gauge needle, if needed a capsulorrhexis forceps was used to complete the procedure ending with approximately $6 \mathrm{~mm}$ wide CCC (fig 1) .

5) 2 side ports were done by a 20 gauge disposable ophthalmic microvitreoretinal blade (MVR) for the second instrument and bimanual I/A latter .

6) Hydrodissection was done by a 27 gauge flat tip hydrodissection canula. After gently elevating the edge of the CCC anteriorly and advancing the tip of the canula, a small amount of irrigation fluid was injected slow and steady until a wave of hydrodissection was seen on the posterior capsule along with gentle downward compression on the nucleus to prevent capsular block syndrome (fig 2).

7) Using the Alcon series 2000 LEGACY phacoemulsification systems, standard tip with $15^{\circ}$ bevel fitted on phaco hand piece was used in all our cases .Divide and conquer technique was done and the following machine parameters were used during making the grove fig (3) (Phaco1).

8) After removal of the whole nucleus, the remaining epinucleus was aspirated using the phaco tip mainly in foot position II setting the vacuum at 100- 150 $\mathrm{mmHg}$ with U/S power $20 \%$ (pulse mode) and AFR $28 \mathrm{mmHg}$.

9) Irrigation and aspiration (I/A) of the cortical matter was then done by a bimanual I/A canula fig (4).

10) After the bag was filled with viscoelastics, a posterior chamber foldable intraocular lens (IOL) was implanted into the bag using a lens injector or foldable lens forceps which may need to be dialed more using sinskey hook or even the viscoelastics canula fig $(5,6,7)$.

11) The wound was closed by stromal hydration.

12) Finally a $1 \mathrm{ml}$ combination of antibiotics and steroid was injected subconjunctivally. 


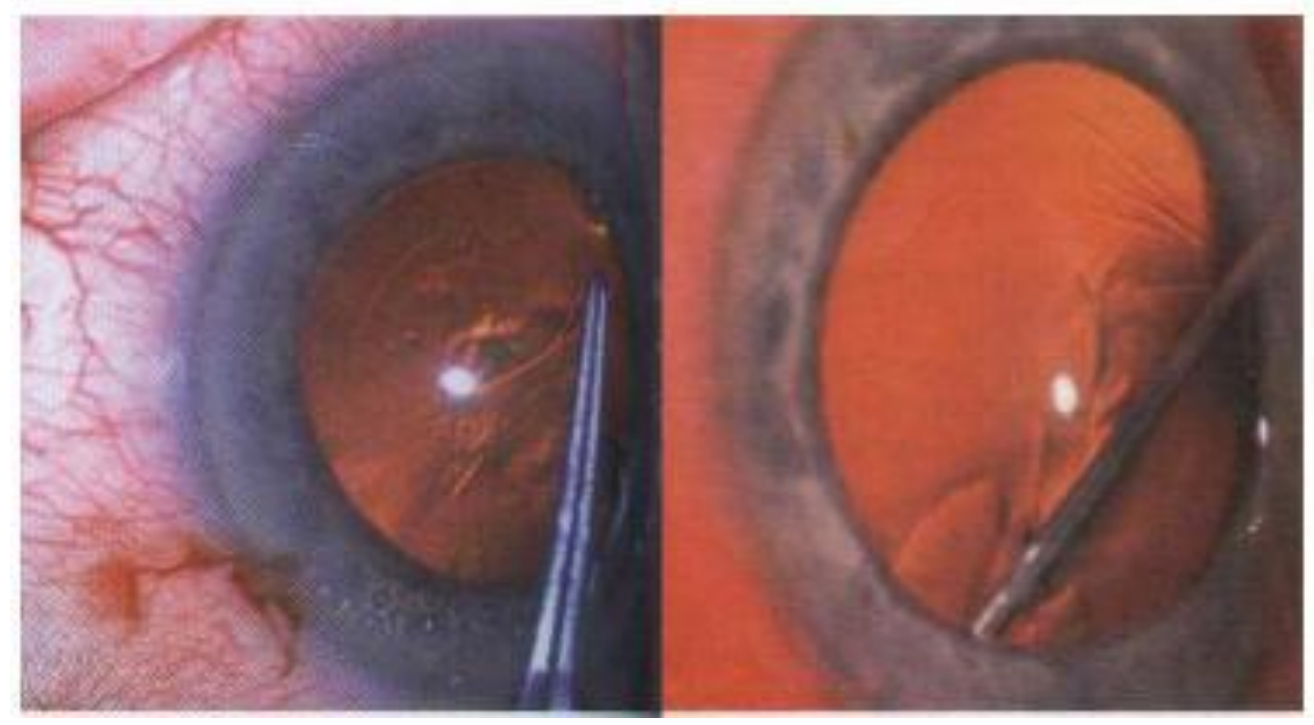

Figure (1): Continuous curvilinear capsulorrhexis. Figure (2): Hydrodissection

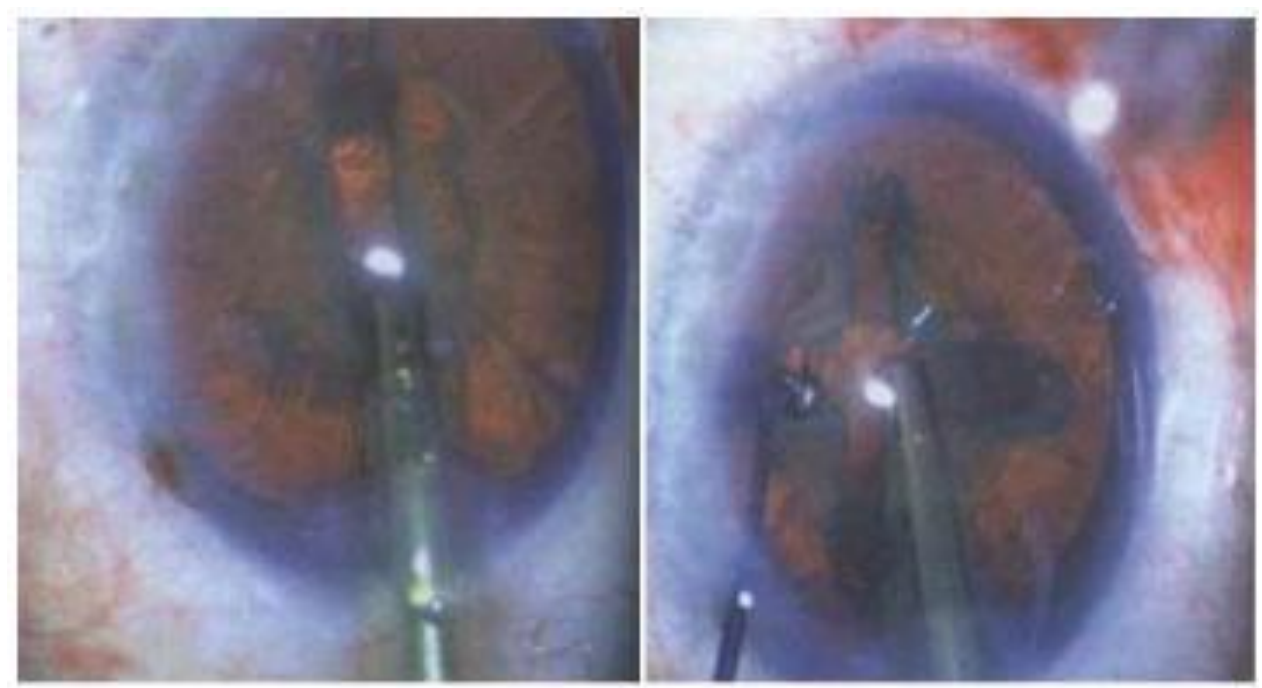

Figure (3): Divide and conquer technique .

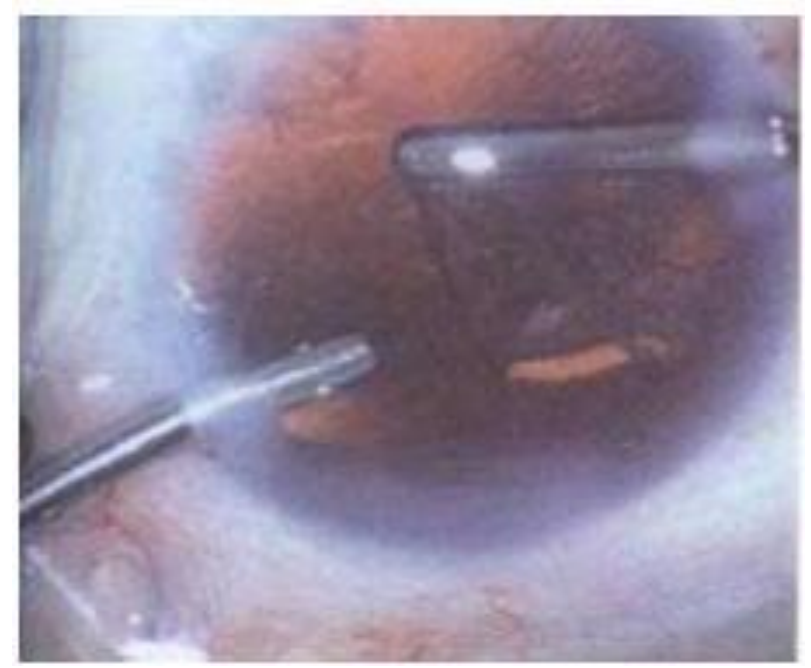

Figure (4): I/A of cortical matter done by a bimanual I/A canula 
ejhm.journals.ekb.eg

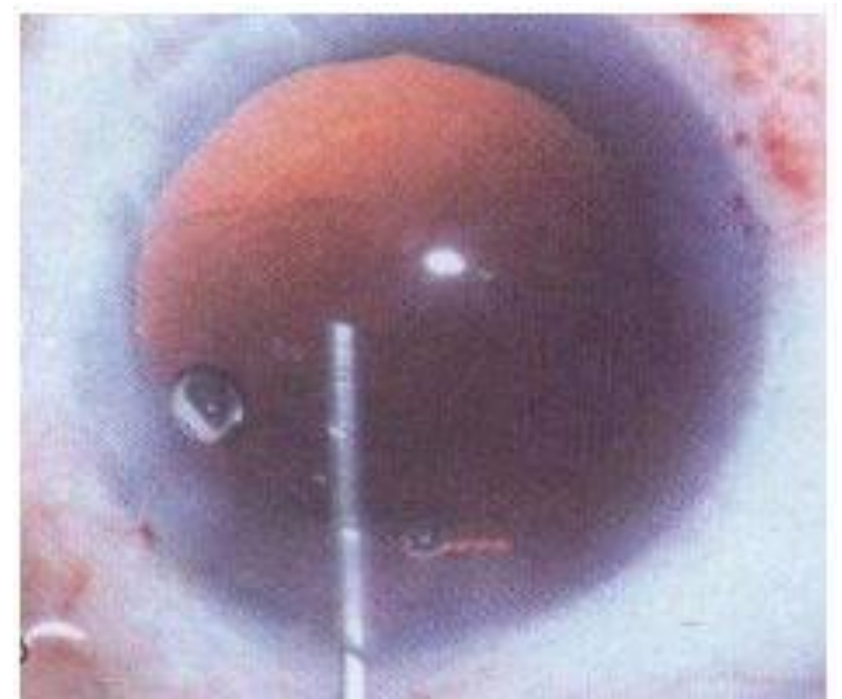

Figure (5): The bag was filled with viscoelastics..

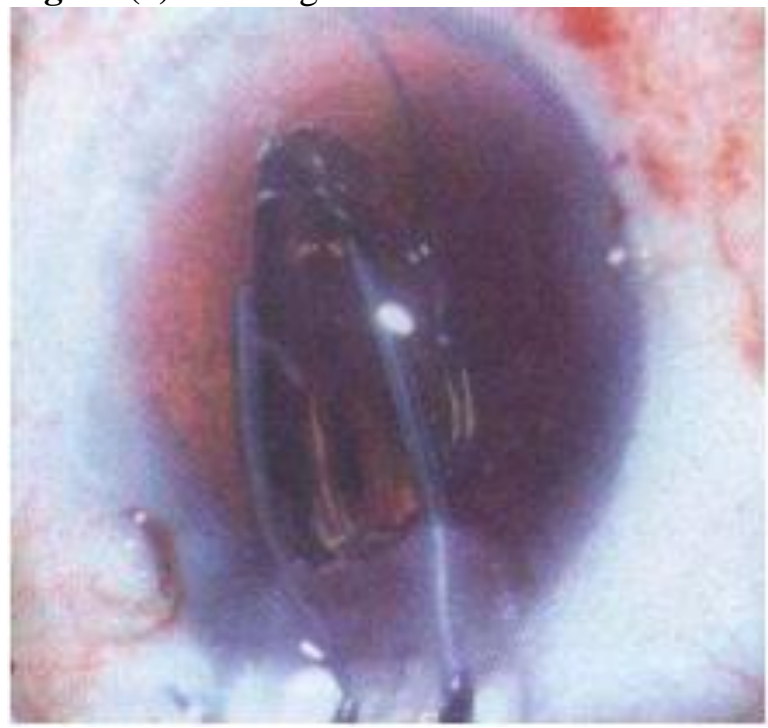

Figure (6): PC foldable IOL implanted into the bagusing forceps .

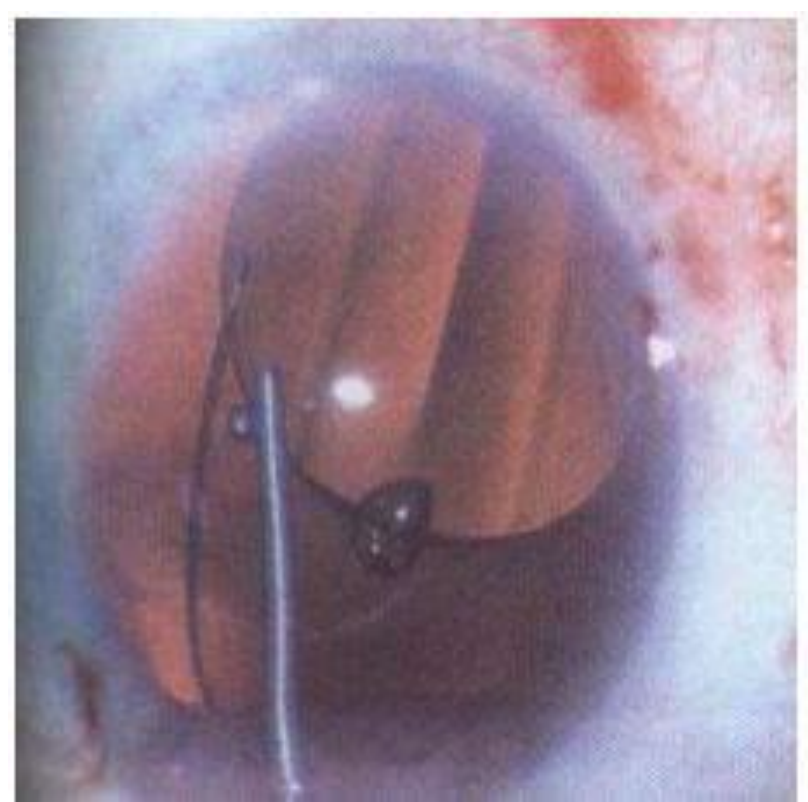

Figure (7): IOL dialing into the capsular bag . 


\section{II) Manual SICS:}

1) Sterilization and draping.

2) Application of a wire speculum.

3) An eight mm periotomy was made superiorly with scissors, fig $(8 \mathrm{a})$. The conjunctiva and the tenon's were dissected separately and bleeding was cleared with a wet field cautery.

4) A linear incision was made with the tip of a crescent blade, blade 15 or a super blade at about 1 $1.5 \mathrm{~mm}$ distance from the limbus, fig $(8 \mathrm{~b}, \mathrm{c})$.

5) The external width of the incision was about 6$6.5 \mathrm{~mm}$ according to the expected size of the nucleus. The incision was dissected forward for 1$1.5 \mathrm{~mm}$ into clear cornea with a bevel-up crescent blade, fig $(8 \mathrm{~d}, \mathrm{e}, \mathrm{f})$.

6) A side port was made with a $15^{\circ}$ super blade then viscoelastic was injected to fill the anterior chamber, fig $(8 \mathrm{~g}, \mathrm{~h})$.

7) The anterior chamber was entered with a $3.2 \mathrm{~mm}$ keratome at the depth of the scleral flap, giving a self-sealing internal flap. Then additional viscoelastic was injected into the anterior chamber, fig $(8 \mathrm{I}, \mathrm{j})$.

8) A CCC was performed with a self-fashioned cystotome using a bent 27 gauge needle and if needed a capsulorrhexis forceps was used to complete the procedure, fig $(8 \mathrm{k})$.

9) Complete hydrodissection was done with the canula just beneath the anterior capsule, to loosen the nucleus and got it rotating freely. Generally one fluid wave to the right and one to the left was adequate, fig $(81)$.

10) The $3.2 \mathrm{~mm}$ incision was enlarged to $8-9 \mathrm{~mm}$ with the crescent blade attempting to maintain the internal self-sealing incision all the way across. Additional viscoelastic was injected in the anterior chamber. The nucleus was prolapsed in the anterior chamber either by viscoexpression or with use of sinskey hook by rotating the nucleus either clockwise or anticlockwise till it was delivered in the anterior chamber, fig $(8 \mathrm{~m})$.

a

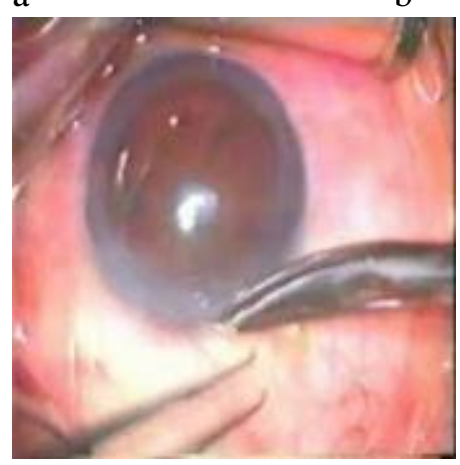

b

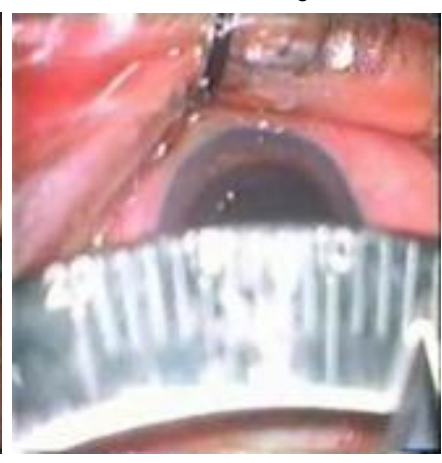

11) Prior to nucleus removal, it was necessary to make sure that the whole nucleus lies in front of the iris then viscoelastics were liberally injected both above and below the nucleus. The upper layer shields the endothelium while the lower layer pushed the posterior capsule and iris diaphragm posteriorly. This created a space for the nontraumatic insertion of the vectis. The vectis was then tested outside for the patency of the ports, fig $(8 n)$.

12) The nucleus was then removed using an irrigating vectis or phaco sandwich technique, fig(8o). The irrigating vectis used was a $5 \mathrm{~mm}$ wide vectis with three $0.3 \mathrm{~mm}$ forward irrigating ports with a gentle superior concavity. This vectis was attached to a $5 \mathrm{cc}$ syringe containing Ringer lactate when in use. The vectis was insinuated, concave side up, under the nucleus. At this point, it was very important to see the margins of the vectis through the nucleus to avoid pinching of the iris and consequent iridodialysis. Now the following movements should occur in synchrony. The irrigating vecris was withdrawn out slowly without irrigating till the superior pole of the nucleus was engaged in the tunnel. At this point, with the globe was fixed the irrigating fluid was injected slowly to build up the hydrostatic pressure inside the chamber and the vectis was slowly pulled out while pressing down on the scleral lip.

13) Irrigation - aspiration of the cortex was then done by Simcoe canula, fig $(8 \mathrm{p})$.

14) Viscoelastic was injected in $A C$ to fill the capsular bag, fig(8q).

15) Posterior chamber $5.5 \mathrm{~mm}$ or $6.5 \mathrm{~mm}$ PMMA intraocular lens (IOL) was implanted into the bag, fig $(8 \mathrm{r})$.

16) The conjunctiva was close with bipolar cautery, fig(8t) or by a single 8-0 nylon stitch if the cauterization was not available and finally a $1 \mathrm{~mm}$ combination of broad spectrum antibiotic and steroid was injected subconjunctivally.
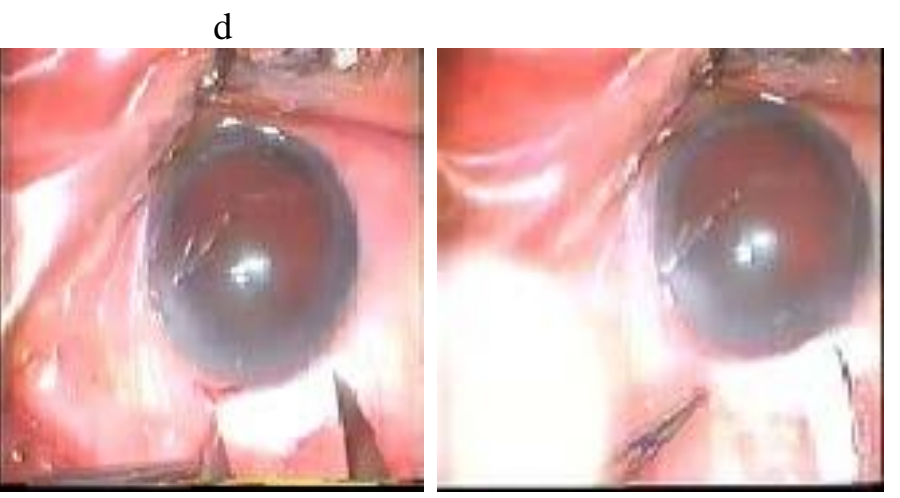

Figure (8): a) Conjunctival incision. b) The caliber opened at $6.5 \mathrm{~mm}$. c) $6.5 \mathrm{~mm}$ scleral incision was done. d) The crescent knife was introduced into the scleral incision. 
e

f

g

$\mathrm{h}$

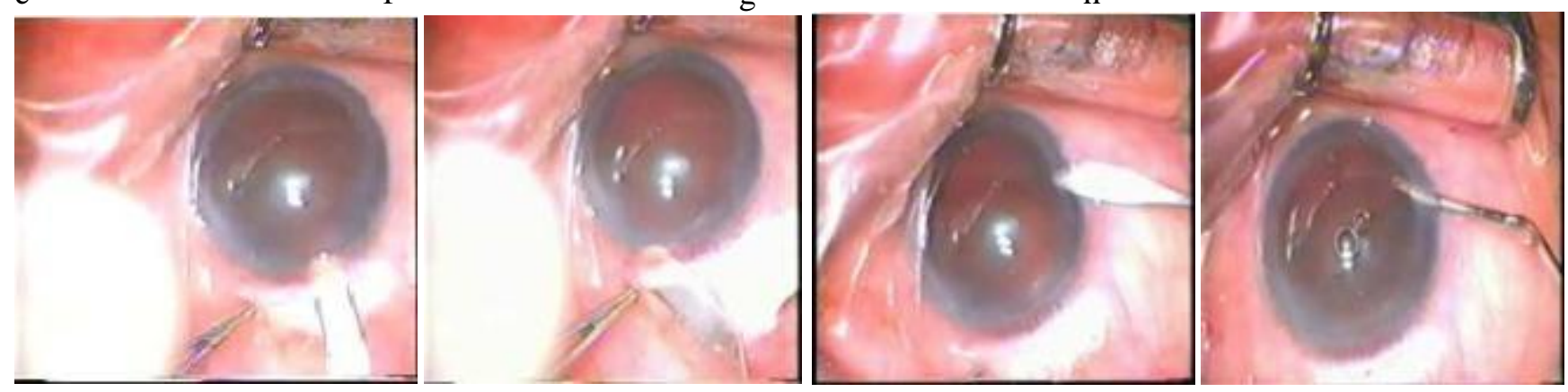

Figure (8): e) Scleral tunnel was fashioned. f) Scleral tunnel wascompleted with lateral extentions from inside. g) A side port wasdone. h) Viscoelastic was injected from the side port.

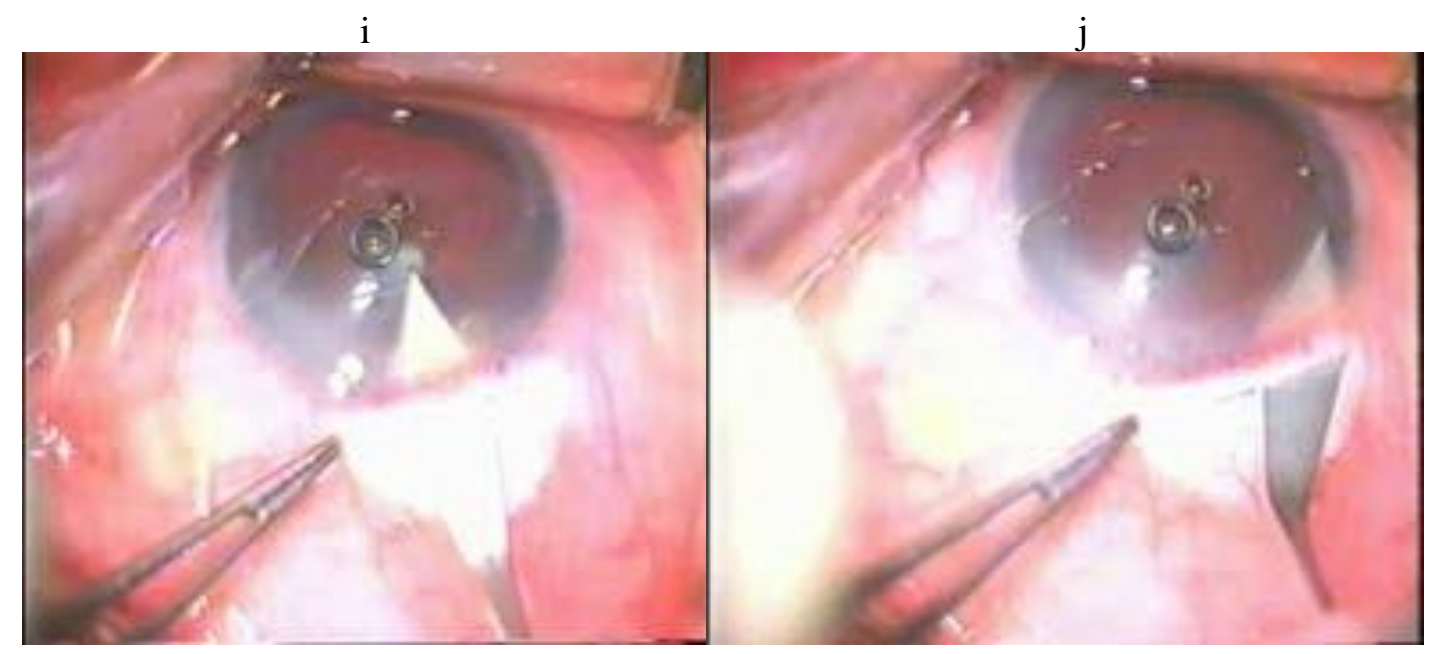

Figure (8): i) AC was entered with a 3.2mm keratome. j) The mainwound was extended to be 8-9mm from inside.
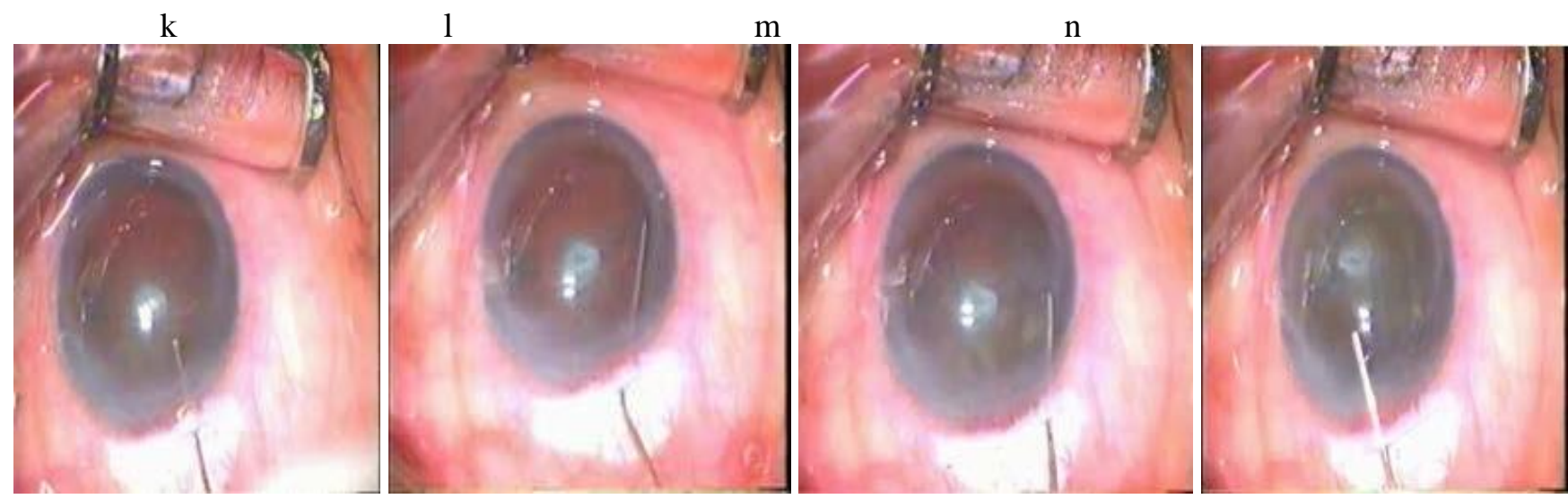

Figure (8): k)Continuous Curvilinear Capsulorrhexis was performedwith cystotome.1) Hydro- dissection is done. $\mathrm{m})$ The lens equator wasengaged by a sinskey hook and the nucleus was rotated and introducedin AC. n)Viscoelastic was generously injected above and below the nucleus . 

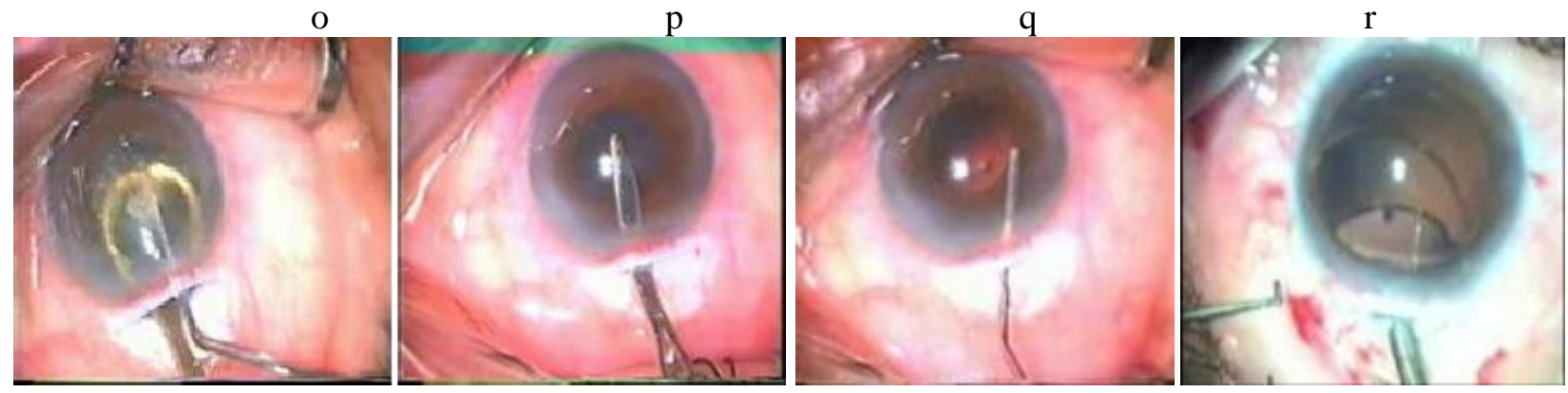

Figure (8): o) The nucleus was sandwiched between the scoop and thesiniskey hook and pulled out of AC. p) I/A of the residual lens matterwas done by a double-way cannula. q) Viscoelastic was injected in AC tofill the capsular bag. r) A $6.5 \mathrm{~mm}$ IOL was introduced into the bag.

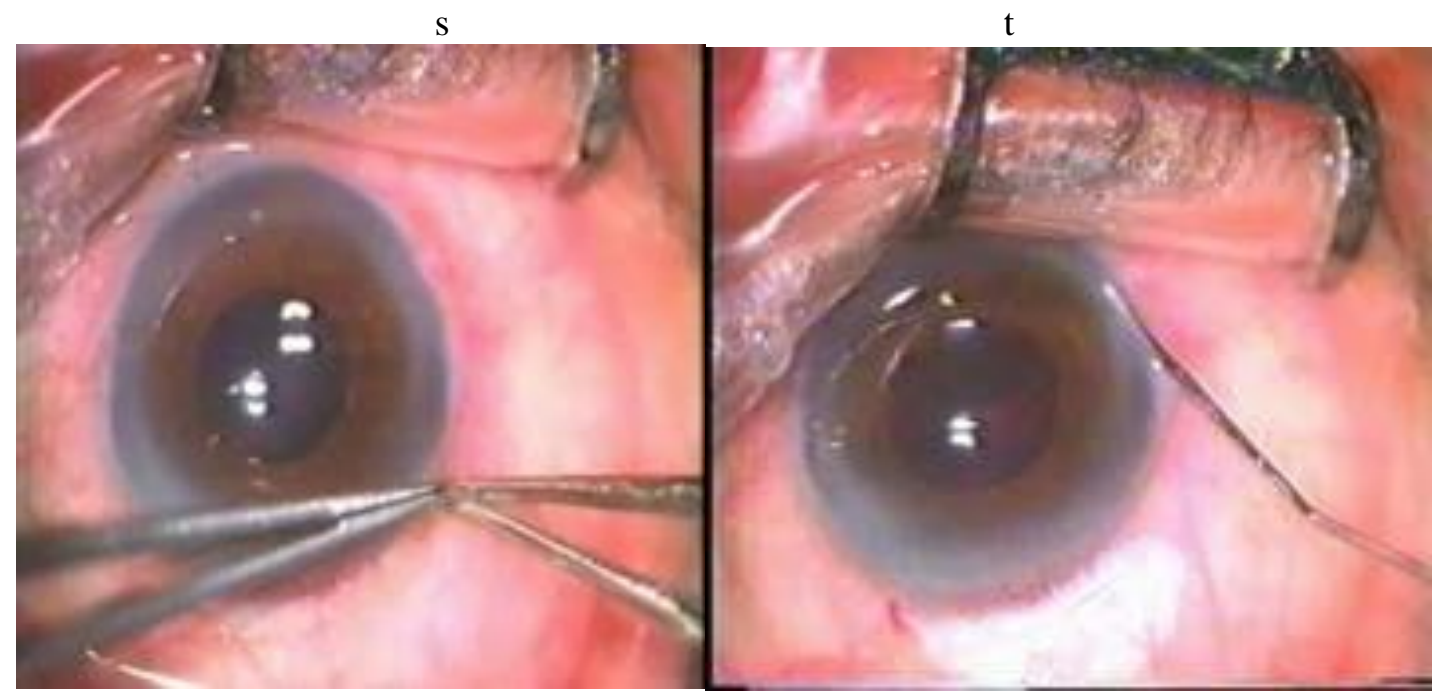

Figure (8): s) Hydration of the side port was done. t) The conjunctiva wasclosed with bipolar cautary.

Figure (8): Steps of MSICS

\section{3- Postoperative Assessment:}

The postoperative treatment, for both groups, was as follows:

- Topical prednisolone acetate 1\% (Optipred) eye drops 6 times daily for one week then tapered gradually over 6 weeks.

- Topical Ofloxacin $0.3 \%$ eye drops 6 times daily for one week then four times per day for 2 weeks.

- Combined Tobramycin with Dexamethasone phosphate $0.1 \%$ eye ointment once before sleep for one week.

The patients were examined on slit lamp for follow up at 24hours, 1 week, 1 month and 3 months after surgery.

\section{Statistical analysis}

Recorded data were analyzed using the statistical package for social sciences, version 20.0
(SPSS Inc., Chicago, Illinois, USA). Quantitative data were expressed as mean \pm standard deviation (SD). Qualitative data were expressed as frequency and percentage.

\section{The following tests were done:}

- Independent-samples t-test of significance was used when comparing between two means.

- Chi-square $\left(\mathrm{x}^{2}\right)$ test of significance was used in order to compare proportions between two qualitative parameters.

- The confidence interval was set to $95 \%$ and the margin of error accepted was set to 5\%. The p-value was considered significant as the following:

- Probability (P-value)

- P-value <0.05 was considered significant.

- P-value <0.001 was considered as highly significant.

- P-value >0.05 was considered insignificant. 


\section{RESULTS}

\section{I) Demographic data \\ 1- Age:}

Mean age in group A is (57.8 \pm 8.66$)$. Its range is $40-76$ years. However, in group B mean age is (58.75 \pm 6.8$)$ and range is 45-76 years. No significant statistical difference is detected between two groups as regards age.

Table (1): Age distribution among the study group

\begin{tabular}{|c|c|c|c|c|c|}
\hline \multirow{4}{*}{ Age } & $\begin{array}{c}\text { Group A } \\
\text { (Phacoemulsification) }\end{array}$ & $\begin{array}{c}\text { Group B } \\
\text { (SICS) }\end{array}$ & $\begin{array}{c}\text { Unpaired - } \\
\text { t-test }\end{array}$ & P value \\
\cline { 2 - 6 } & $\begin{array}{c}\text { Mean } \pm \\
\text { SD }\end{array}$ & $57.8 \pm 8.66$ & $58.75 \pm 6.8$ & 0.386 & \multirow{2}{*}{0.702} \\
\cline { 2 - 4 } & Range & $40-76$ & $45-67$ & 6.541 & 0 \\
\hline
\end{tabular}

\section{2- Gender:}

In group A, there are $12(60 \%)$ males, and 8 (40\%) females. However, in group B, there are $7(35 \%)$ males, and $13(65 \%)$ females. No significant statistical difference is detected between two groups as regards gender.

Table (2): Gender distribution of both groups

\begin{tabular}{|c|c|c|c|c|c|}
\hline \multirow[b]{2}{*}{ Gender } & \multicolumn{2}{|l|}{ Groups } & \multirow[b]{2}{*}{ Total } & \multirow{2}{*}{$\begin{array}{c}\text { Chi-square with Yates } \\
\text { correction }\left(\mathrm{x}^{2}\right)\end{array}$} & \multirow{2}{*}{$\begin{array}{c}\mathrm{P} \\
\text { value }\end{array}$} \\
\hline & $\begin{array}{c}\text { Group A } \\
\text { (Phacoemulsification) }\end{array}$ & $\begin{array}{c}\text { Group B } \\
\text { (SICS) }\end{array}$ & & & \\
\hline Female & 8 & 13 & 21 & \multirow{3}{*}{1.604} & \multirow{3}{*}{0.205} \\
\hline Male & 12 & 7 & 19 & & \\
\hline Total & 20 & 20 & 40 & & \\
\hline
\end{tabular}

\section{II) Visual acuity:-}

a) Comparison of V/A between group $A$ and B:-

- UCVA :-

As regards pre-operative UCVA, the mean is $(0.15 \pm 0.13)$ and $(0.11 \pm 0.098)$ in group $\mathrm{A}$ and $\mathrm{B}$ respectively, and the range in both groups is $\mathrm{HM}$ -0.4 .

While as regards post-operative UCVA, after one week the mean is $(0.7 \pm 0.2),(0.745 \pm$ $0.16)$ and the range is $0.3-1,0.4-1$ in group $A$ and $\mathrm{B}$ respectively while after 1 month post-operative, the mean of UCVA is $(0.73 \pm 0.21),(0.77 \pm 0.15)$ and the range is $0.3-1,0.4-1$ in group $\mathrm{A}$ and $\mathrm{B}$ respectively and after 3 months post-operative UCVA mean is $(0.765 \pm 0.2),(0.77 \pm 0.15)$ in group A and B respectively, and the range is 0.4 1 in both groups.

No significant statistical difference is detected between group $\mathrm{A}$ and $\mathrm{B}$ as regards UCVA in different follow up visits.

\section{- BCVA:}

As regards pre-operative $\mathrm{BCVA}$, the mean is $(0.29 \pm 0.18)$ and $(0.17 \pm 0.15)$ in group $A$ and $\mathrm{B}$ respectively, and range in both groups is $\mathrm{HM}$ 0.5 .

While as regards post-operative BCVA, after one week the mean is $(0.775 \pm 0.15)$ and $(0.77 \pm 0.13)$, and the range is $0.6-1,0.5-1$ in group A and B respectively while after 1 month post-operative, the mean of BCVA is $(0.81 \pm$ $0.16),(0.775 \pm 0.13)$ and the range is $0.6-1$ and 0.5-1 in group A and B respectively and after 3 months post-operative BCVA mean is $(0.81 \pm$ $0.16),(0.775 \pm 0.13)$ in group $\mathrm{A}$ and $\mathrm{B}$ respectively, and the range is $0.6-1,0.5-1$ in group A and B respectively.

No significant statistical difference is detected between group A and B as regards BCVA in different follow up visits. 
Table (3): Comparison of preoperative \& postoperative V/A between group A \& B

\begin{tabular}{|c|c|c|c|c|c|c|}
\hline & \multicolumn{2}{|c|}{ V/A } & $\begin{array}{c}\text { Group } \\
\text { A }(\text { Phacoemu }\end{array}$ & $\begin{array}{c}\text { Group B } \\
\text { (SICS) }\end{array}$ & $\begin{array}{c}\text { Mann- } \\
\text { Whitney }\end{array}$ & $\begin{array}{c}\mathbf{P} \\
\text { value }\end{array}$ \\
\hline \multirow{4}{*}{$\begin{array}{c}\text { Pre- } \\
\text { operative }\end{array}$} & \multirow{2}{*}{$\begin{array}{c}\text { UCV } \\
\mathbf{A}\end{array}$} & $\begin{array}{c}\text { Mean } \pm \\
\text { SD }\end{array}$ & $0.15 \pm 0.13$ & $0.11 \pm 0.098$ & \multirow[t]{2}{*}{1.1} & \multirow[t]{2}{*}{0.271} \\
\hline & & Range & $0.00167-0.4$ & $0.00167-0.4$ & & \\
\hline & \multirow{2}{*}{$\begin{array}{c}\text { BCV } \\
\mathbf{A}\end{array}$} & $\begin{array}{l}\text { Mean } \pm \\
\text { SD }\end{array}$ & $0.29 \pm 0.18$ & $0.17 \pm 0.15$ & \multirow{2}{*}{1.65} & \multirow[t]{2}{*}{0.099} \\
\hline & & Range & $0.00167-0.5$ & $0.00167-0.5$ & & \\
\hline \multirow{4}{*}{$\begin{array}{l}\text { Post. } \\
1 \text { week }\end{array}$} & \multirow{2}{*}{$\begin{array}{c}\text { UCV } \\
\mathbf{A}\end{array}$} & $\begin{array}{c}\text { Mean } \pm \\
\text { SD }\end{array}$ & $0.7 \pm 0.2$ & $0.745 \pm 0.16$ & \multirow[t]{2}{*}{0.151} & \multirow{2}{*}{0.88} \\
\hline & & Range & $0.3-1$ & $0.4-1$ & & \\
\hline & \multirow{2}{*}{$\begin{array}{c}\text { BCV } \\
\mathbf{A}\end{array}$} & $\underset{\text { SD }}{\operatorname{Mean} \pm}$ & $0.775 \pm 0.15$ & $0.77 \pm 0.13$ & \multirow[t]{2}{*}{0.083} & \multirow[t]{2}{*}{0.934} \\
\hline & & Range & $0.6-1$ & $0.5-1$ & & \\
\hline \multirow{4}{*}{$\begin{array}{l}\text { Post. } \\
1 \text { month }\end{array}$} & \multirow{2}{*}{$\begin{array}{c}\mathbf{U C V} \\
\mathbf{A}\end{array}$} & $\begin{array}{l}\text { Mean } \pm \\
\text { SD }\end{array}$ & $0.73 \pm 0.21$ & $0.77 \pm 0.15$ & \multirow{2}{*}{0.069} & \multirow{2}{*}{0.945} \\
\hline & & Range & $0.3-1$ & $0.4-1$ & & \\
\hline & \multirow{2}{*}{$\begin{array}{c}\text { BCV } \\
\mathbf{A}\end{array}$} & $\begin{array}{c}\text { Mean } \pm \\
\text { SD }\end{array}$ & $0.81 \pm 0.16$ & $0.775 \pm 0.13$ & \multirow{2}{*}{0.663} & \multirow{2}{*}{0.507} \\
\hline & & Range & $0.6-1$ & $0.5-1$ & & \\
\hline \multirow{4}{*}{$\begin{array}{c}\text { Post. } \\
3 \\
\text { months }\end{array}$} & \multirow{2}{*}{$\begin{array}{c}\mathbf{U C V} \\
\mathbf{A}\end{array}$} & $\begin{array}{c}\text { Mean } \pm \\
\text { SD }\end{array}$ & $0.765 \pm 0.2$ & $0.77 \pm 0.15$ & \multirow[t]{2}{*}{0.083} & \multirow[t]{2}{*}{0.934} \\
\hline & & Range & $0.4-1$ & $0.4-1$ & & \\
\hline & \multirow{2}{*}{$\begin{array}{c}\mathbf{B C V} \\
\mathbf{A}\end{array}$} & $\underset{\text { SD }}{\operatorname{Mean} \pm}$ & $0.81 \pm 0.16$ & $0.775 \pm 0.13$ & \multirow[t]{2}{*}{0.663} & \multirow[t]{2}{*}{0.507} \\
\hline & & Range & $0.6-1$ & $0.5-1$ & & \\
\hline
\end{tabular}

b) Comparison of V/A within group A:

- UCVA:

UCVA has increased significantly one week postoperative in comparison to preoperative $(p=0.001)$. However, no significant statistical difference has been detected between different postoperative follow up visits.

Table (4): Comparison of preoperative \& postoperative UCVA in group A

\begin{tabular}{|c|c|c|c|}
\hline \multirow{3}{*}{$\begin{array}{c}\text { UCVA (all } \\
\text { follow } \\
\text { up) }\end{array}$} & Pre-operative & Freidman test $\left(\mathrm{x}^{2}\right)$ & P value \\
\cline { 2 - 3 } & Post. 1 week & & \\
\cline { 2 - 4 } & Post. 1 month & 55.432 & $<0.001^{*}$ \\
\cline { 2 - 4 } & Post. 3 months & & \\
\hline \multirow{3}{*}{$\begin{array}{c}\text { Every two } \\
\text { reading }\end{array}$} & Pre \& post 1 week & Wilcoxon ranks test $(\mathrm{z})$ & P value \\
\cline { 2 - 4 } & post 1 week \& 1 month & $\mathbf{3 . 9 2 5}$ & $\mathbf{0 . 0 0 1 *}$ \\
\cline { 2 - 4 } & post 1 week \& 3 months & $\mathbf{1 . 6 3 3}$ & $\mathbf{0 . 0 5 9}$ \\
\hline
\end{tabular}

BCVA:

BCVA has increased significantly one week postoperative in comparison to preoperative $(p=0.001)$. However, no significant statistical difference has been detected between different postoperative follow up visits. 
Table (5): Comparison of preoperative \& postoperative BCVA in group A

\begin{tabular}{|c|c|c|c|}
\hline \multirow{4}{*}{$\begin{array}{c}\text { BCVA (all } \\
\text { follow up }\end{array}$} & Pre-operative & Freidman test $\left(\mathrm{x}^{2}\right)$ & P value \\
\cline { 2 - 4 } & Post. 1 week & & \\
& Post. 1 month & 56.442 & $<0.001^{*}$ \\
\cline { 2 - 4 } & Post. 3 months & & \\
\hline & & & P value \\
\hline \multirow{3}{*}{$\begin{array}{c}\text { Every two } \\
\text { reading }\end{array}$} & Pre \& post 1 week & $\mathbf{3 . 9 2 6}$ & $\mathbf{0 . 0 0 1 *}$ \\
\cline { 2 - 4 } & post 1 week \& 1 month & $\mathbf{1 . 6 3 3}$ & $\mathbf{0 . 1 0 2}$ \\
\cline { 2 - 4 } & post 1 week \& 3 months & $\mathbf{1 . 6 3 3}$ \\
\hline
\end{tabular}

c) Comparison of V/A within group B:

- UCVA:

UCVA has increased significantly one week postoperative in comparison to preoperative $(\mathrm{p}=0.001)$. However, no significant statistical difference has been detected between different postoperative follow up visits.

Table (6): Comparison of preoperative \& postoperative UCVA in group B

\begin{tabular}{|c|c|c|c|}
\hline \multirow{5}{*}{$\begin{array}{l}\text { UCVA (all } \\
\text { follow up) }\end{array}$} & & Freidman test $\left(\mathrm{x}^{2}\right)$ & $\mathrm{P}$ value \\
\hline & Pre-operative & \multirow{4}{*}{56.442} & \multirow{4}{*}{$<0.001 *$} \\
\hline & Post. 1 week & & \\
\hline & Post. 1 month & & \\
\hline & Post. 3 months & & \\
\hline \multirow{4}{*}{$\begin{array}{l}\text { Every } \\
\text { reading }\end{array}$} & & Wilcoxon ranks test $(\mathrm{z})$ & $P$ value \\
\hline & Pre \& post 1 week & 3.923 & $<0.001 *$ \\
\hline & post 1 week \& 1 month & 1.633 & 0.102 \\
\hline & post 1 week \& 3 months & 1.633 & 0.102 \\
\hline
\end{tabular}

- BCVA:

BCVA has increased significantly one week postoperative in comparison to preoperative $(\mathrm{p}=0.001)$. However, no significant statistical difference has been detected between different postoperative follow up visits.

Table (7): Comparison of preoperative \& postoperative BCVA in group B

\begin{tabular}{|c|c|c|c|}
\hline \multirow{2}{*}{$\begin{array}{c}\text { BCVA } \\
\text { (all } \\
\text { follow } \\
\text { up) }\end{array}$} & Pre-operative & Freidman test $\left(\mathrm{x}^{2}\right)$ & P value \\
\cline { 2 - 3 } & Post. 1 week & & \\
\cline { 2 - 4 } & Post. 1 month & 58.61 & $<0.001^{*}$ \\
\cline { 2 - 4 } & Post. 3 months & & \\
\hline \multirow{2}{*}{$\begin{array}{c}\text { Every } \\
\text { two } \\
\text { reading }\end{array}$} & Pre \& post 1 week & Wilcoxon ranks test $(\mathrm{z})$ & P value \\
\cline { 2 - 4 } & post 1 week \& 1 month & $\mathbf{3 . 9 2 7}$ & $\mathbf{0 . 0 0 1} *$ \\
\cline { 2 - 4 } & post 1 week \& 3 months & $\mathbf{1 . 0 0}$ & $\mathbf{0 . 3 1 7}$ \\
\hline
\end{tabular}

c) Comparison of SIA between group A and B:

As regards 1 week postoperative SIA, mean is $(0.497 \pm 0.21)$ and $(0.83 \pm 0.64)$ in group A and B respectively, while after 1 month the SIA mean is $(0.415 \pm 0.23)$ and $(0.68 \pm 0.55)$ in group A and B respectively ,and after3 months the SIA mean is $(0.43 \pm 0.25)$ and $(0.61 \pm 0.55)$ in group A and B respectively. No significant statistical difference is detected between group A and B as regards SIA in different follow up visits.

Table (8): Comparison of SIA between group A and B

\begin{tabular}{|c|c|c|c|c|c|}
\hline \multicolumn{2}{|c|}{ SIA } & $\begin{array}{c}\text { Group A(Phacoe- } \\
\text { mulsification) }\end{array}$ & $\begin{array}{c}\text { Group B } \\
\text { (SICS) }\end{array}$ & $\begin{array}{c}\text { Mann-Whitney } \\
\text { test (z) }\end{array}$ & $\begin{array}{c}\text { P } \\
\text { value }\end{array}$ \\
\hline \multirow{2}{*}{$\begin{array}{c}\text { Post. 1 } \\
\text { week }\end{array}$} & Mean \pm SD & $0.497 \pm 0.21$ & $0.83 \pm 0.64$ & 1.476 & 0.14 \\
\cline { 2 - 4 } $\begin{array}{c}\text { Post. 1 } \\
\text { month }\end{array}$ & Range & $0.17-0.92$ & $0.21-2.32$ & & \\
\cline { 2 - 4 } Post. 3 & Range & $0.415 \pm 0.23$ & $0.68 \pm 0.55$ & 2.02 & 0.05 \\
months & Mean \pm SD & $0.13-1$ & $0.17-2.32$ & & 0.348 \\
\cline { 2 - 4 } & Range & $0.13 \pm 0.25$ & $0.61 \pm 0.55$ & 0.938 & \\
\hline
\end{tabular}




\section{DISCUSSION}

In this study, we compared the two techniques phacoemulsification (group A) and MSICS (group B) as regard their effect on the postoperative visual outcome and SIA.

1) Age :

The mean age in group A is $57.8 \pm 8.66$ while in group $\mathrm{B}$ is $58.75 \pm 6.8$. Therefore, no significant statistical difference between the two groups as regards the age. This was important when comparing the astigmatic effect between the two groups as the relaxing effect of an incision varies with the age of the patient.

\section{2) Visual acuity:}

In this study the preoperative visual acuity was almost similar in both groups. After 3 months of surgery both techniques achieved excellent visual outcome with mean BCVA $0.81 \pm 0.16$ in group A and $0.775 \pm 0.13$ in group B so there was no statistical significance of BCVA between both groups.

Ruit et $\boldsymbol{a l} .{ }^{(7)}$ compared the efficacy and visual results of phacoemulsification vs. MSICS for the treatment of cataracts. They compared different parameters including UCVA and BCVA. They found that both the surgical techniques achieved excellent visual outcomes with low complication rates. At six months $85 \%$ of the SICS patients had UCVA of 20/60 or better and $98 \%$ had a BCVA of $20 / 60$ or better vs. $82 \%$ of patients with UCVA of $20 / 60$ or better and $98 \%$ of patients with BCVA of $20 / 60$ or better at six months in the phaco group. They also mentioned that the surgical time for SICS was much shorter than that for phacoemulsification and they concluded that SICS is an appropriate surgical procedure for the treatment of advanced cataracts.

Venkatesh et al. ${ }^{(8)}$ were concerned with the article of Gogate $\boldsymbol{e t} \boldsymbol{a l} \cdot{ }^{(9)}$ as regard the UCVA at the 6-weeks follow- up visit. The results of the study states that the UCVA was $20 / 60$ or better in 99 patients $(87.6 \%)$ in the phacoemulsification group and 96 patients $(82.0 \%)$ in the manual SICS group $(\mathrm{P}=0.10)$ and the BCVA was $20 / 60$ or better in $112(99.0 \%)$ and $115(98.2 \%)$, respectively $(\mathrm{P}=0.59)$ so they concluded that MSICS is significantly less expensive, and less technology-dependent than phacoemulsification, it may be a more appropriate technique in eyes with mature cataract in the developing world.

Another study done in the same institute comparing ECCE and manual SICS has quoted an UCVA of $\geq 6 / 18$ in $47.9 \%$ at the 6-week follow-up visit in ECCE group ${ }^{(\mathbf{1 0})}$.

Guzek et $\boldsymbol{a l} .{ }^{(11)}$ in his study on 200 eyes undergoing suturless SICS found that $90 \%$ of eyes achieved a final BCVA of at least 6/12. In addition, patients had a faster visual recovery and lower incidence of ocular inflammation particularly fibrinous iritis, a result which is very close to the results of our study.

3) Surgical induced astigmatism (SIA) :-
In our study we compared the mean SIA inside each group and between the two studied groups at one week, one month and 3 months. The mean SIA in group A was $0.497 \pm 0.21,0.415 \pm 0.23$ and $0.43 \pm 0.25$ at 1 week, 1 month and 3 months respectively while in group B was $0.83 \pm 0.64,0.68 \pm 0.55$ and $0.61 \pm 0.55$ respectively.

We found that the mean SIA value decreased inside each group along the 3 months but with higher quantitative value in MSICS group (B). However, there was no statistical difference inside each group and between both groups regarding the mean SIA.

In Gogate et $^{\text {al }}{ }^{(\mathbf{9 )}}$ study, total of 400 eyes was assigned randomly to either phacoemulsification or small-incision groups were operated on by 4 surgeons. Average astigmatism for the phacoemulsification group was 1.1 diopters and for the small-incision group it was 1.2 diopters.

They concluded that phacoemulsification induced less astigmatism than SICS which is agree with our study, but in our study the results are better than this study which may be because the surgeries were operated by 4 surgeons while in ours were operated by the same surgeon.

Reddy et al. ${ }^{(12)}$ compared the astigmatism induced by a superior and temporal incision in MSICS, and the astigmatism induced by clear corneal incision versus scleral tunnel in phacoemulsification surgery. A total of 64 eyes were randomly divided into two groups. Group I had undergone MSICS and Group II had undergone phacoemulsification. The MSICS group patients were randomly subdivided into group Ia received superior incision while group Ib received temporal incision. The phacoemulsification group also was randomly subdivided into two groups group IIa received clear corneal incision and group IIb received scleral pocket incision.

At 90 days, conventional SICS superior incisions gave $1.92 \pm 0.53 \mathrm{D}$ against the rule and temporal incisions $1.57 \pm 0.24 \mathrm{D}$ with the rule astigmatism. Phacoemulsification clear corneal incisions showed 1.08 $\pm 0.36 \mathrm{D}$ and scleral pocket $1.23 \pm 0.71 \mathrm{D}$ astigmatism. In this study the SIA was calculated by substraction method while in our study computer software was used in SIA calculation.

In Zawar et $\boldsymbol{a l} .^{(\mathbf{1 3})}$ study; two thousand eyes were operated by temporal manual small incision suturless technique. At 6 weeks, 1876 (93.8\%) eyes had with-therule and $134(6.2 \%)$ against-the-rule astigmatism (mean $0.7 \pm 1.25 \mathrm{D}$ ) which is almost similar to SIA of MSICS in our study.

In Gogate et al. ${ }^{(14)}$ meta-analysis seven studies evaluated 1303 eyes, comparing surgically induced astigmatism after phacoemulsification and SICS. Phacoemulsification had statistically significantly lower than SICS $(\mathrm{P}=0.005)$. This study is consistent with that we conducted as phacoemulsification induces SIA lessthan MSICS while it disagrees with ours that there 
was no statistical significance of SIA between both techniques at 3 months ( $p=0.348$ ). This is because the type of this study differs from the one we conducted.

\section{CONCLUSION}

Early visual rehabilitation after cataract surgery was one of major advantages offered by phacoemulsification surgery, this was mainly attributed to the small incision size used. But, phacoemulsification may not be an affordable technique in the developing countries due to its high cost which is one of the most important barriers to cataract surgery. So MSICS with its suturless and relatively smaller incision has similar advantages to phacoemulsification and is affordable; hence, it is a good alternative to phacoemulsification especially in developing countries.

In our hands, and using the techniques and instrumentations described in this thesis, we came to the following conclusions:-

We found that both techniques give excellent visual results with no statistical difference of both the phacoemulsification group and the MSICS group attained mean BCVA $0.81 \pm 0.16$ and $0.775 \pm 0.13$ respectively of at the three-month follow-up visit. Also we found that the mean surgically induced astigmatism at the three-month follow up visit was $0.43 \pm 0.25$ in phacoemulsification group while $0.61 \pm 0.55$ in MSICS group with no statistical difference between both of them

Both techniques were associated with a usual rate of AC reaction but with moderate to severe reaction may be seen in few cases in the phacoemulsification group especially those with hard cataracts who were associated also with moderate corneal edema which was resolved with intensive medication after one week of surgery.

Transition to phacoemulsification is easier if one has mastered MSICS, as the surgeon will be familiar with steps such as scleral pocket incision, capsulorhexis and hydro procedures. Familiarity with these steps helps to reduce the incidence of complications while learning phacoemulsification.

So it is very important to master MSICS either for beginners to be like a step for learning phacoemulsification later on or even for expert surgeons who already master phacoemulsification to be like an extra weapon if they need to convert during surgery to get much better results than extra-capsular cataract extraction or to be their first choice in cases with very hard nuclei.

\section{REFERENCES}

1. Muhammad A and Muhammad I (2013): Change in intraocular pressure following phacoemulsification technique of cataract surgery. Ophthalmology Update, 11:1.

2. Das M, Murlikrishnan R and Prashanth S (2005): Manual small incision cataract surgery in eye with white cataracts. Indian J Ophthalmol., 53(3): 173-6.

3. Howard J, Olson $R$ and Soscia $W$ (2002): Microphacoemulsification with white star: a wound-temperature study. J Cataract Refract Surg., 28:1044-1046.

4. Brint S, Steinert $R$ and White $S$ (1991): Astigmatism after small incision cataract surgery: a prospective, randomized, multicenter comparison of 4- and 6.5-mm incisions. Ophthalmology, 98:417-424.

5. Pankaj R, Rajesh P and Ronnie G (2005): Comparison of endothelial cell loss and surgically induced astigmatism following conventional extracapsular cataract surgery, manual small-incision surgery and phacoemulsification. Ophthalmic Epidemiol., 12:293-297.

6. Chang D, Krishnan $K$ and Ravindran $R$ (2010): Phacoemulsification versus manual small-incision cataract surgery for white cataract. J Cataract Refract Surg., 36: 18491854.

7. Ruit S, Tabin G, Chang D et al. (2007): A prospective randomized clinical trial of phacoemulsification vs. manual sutureless small-incision extracapsular cataract surgery in Nepal. Am J Ophthalmol., 143:328.

8. Venkatesh R, Tan CS, Sengupta $S$ et al. (2010): Phacoemulsification versus manual small-incision cataract surgery for white cataract. J Cataract Refract Surg., 36(11):1849-54.

9. Gogate P, Kulkarni S, Krishnaiah S et al. (2005): Safety and efficacy of phacoemulsification compared with manual smallincision cataract surgery by a randomized controlled clinical trial: Six-week results. Ophthalmology, 112: 869-74.

10. Gogate $P$, Deshpande $M$ and Wormald $R$ (2003): Extracapsular cataract surgery compared with manual small incision cataract surgery in community eye care setting in western India: a randomised controlled trial. Br J Ophthalmol., 87: 667-72.

11. Guzek J, Ching A (2003): Small incision manual extracapsular cataract surgery in Ghana, West Africa. J Cataract Refract Surg., 29(1): 57-64.

12. Reddy B,Raj A and Singh VP (2007): Site of incision and corneal astigmatism in conventional SICS versus phacoemulsification. Annals of Ophthalmology, 39(3):209216.

13. Zawar SV, Gogate $P$ (2011): Safety and efficacy of temporal manual small incision cataract surgery in India. Eur $\mathbf{J}$ Ophthalmol.,

21(6):74853.

14. Gogate PM, Jyoti JB, Swapna D et al. (2015): Meta-analysis to Compare the Safety and Efficacy of Manual Small Incision Cataract Surgery and Phacoemulsification. Middle East Afr J Ophthalmol., 22(3): 362-369. 